\title{
TNF Transduced TIL
}

National Cancer Institute

\section{Source}

National Cancer Institute. TNF Transduced TIL. NCI Thesaurus. Code C29482.

A preparation of autologous tumor-infiltrating lymphocytes (TILs) that have been transduced with a retroviral vector encoding the gene for tumor necrosis factor (TNF), a cytokine with anti-angiogenic and cytotoxic activity. Following genetic modification, the lymphocytes are returned to the patient, infiltrate the tumor site, and deliver TNF directly to the tumor site, thereby exerting a specific antitumor effect, and avoiding TNF-related systemic toxicity. ( $\mathrm{NCl} 04)$ 